\title{
Den kvinnliga sopranen i barockrepertoaren
}

\author{
Lectio praecursoria
}

\begin{abstract}
Den offentliga granskningen av Kajsa Dahlbäcks konstnärliga doktorsexamen ägde rum den 28 november 2020 i Sibelius-Akademins konsertsal. Det konstnärliga lärdoms- och färdighetsprovets titel: "Den kvinnliga sopranen i barockrepertoaren". Avhandlingens titel: Sjunga-i-världen - en fenomenologisk betraktelse över sångarens inre arbete. Nämndens ordförande, MuD Assi Karttunen läste upp utlåtandet om det konstnärliga lärdomsoch färdighetsprovet. Universitetslektor, docent Susanna Välimäki gav sitt utlåtande om avhandlingen. Kustos för granskningen var professor, FD Anne Kauppala. Musiken uppfördes av Kajsa Dahlbäck och ensemblen Earthly Angels.
\end{abstract}

Musikprogram i anslutning till lectio:

Rosa Giacinta Badalla: Non plangete (ca. 1660-ca. 1710)

Joseph Chabanceau de la Barre: Vous demandez pour qui mon coeur soûpire (1633-1678)

Georg Friedrich Händel: "Tornami a vagheggiar" ur operan Alcina

(1685-1759)

\section{DEN KVINNLIGA SOPRANEN OCH SAMARBETET MED BAROCKENSEMBLEN - EN ÖVERSIKT}

Utgångspunkten för min doktorsexamen var min erfarenhet som sångerska specialiserad på barockmusik och de gängse arbetssätt vi har inom branschen. Detta har i synnerhet inneburit en tydlig kammarmusikalisk inställning till arbetet.

I konsertserien har jag tillsammans med olika ensembler, orkestrar och körer framfört olika typer av repertoar för kvinnlig sopran från tidsperioden 1600-1750 och från omgivningar där kvinnliga sångare tillåtits verka professionellt. Jag använder här verbet "tillåta" eftersom det visat sig att ifrågavarande sångerskor varit beroende av ett godkännande från män i ledande positioner, exempelvis biskopar, för att kunna utöva sitt musikerskap. 
Avhandlingens utgångspunkt var det inre arbete som den professionella sångaren idkar för att vara samsjungen med instrumentalisterna, behärska sitt eget instrument och den musikaliska tolkningen. Det inre arbetet har varit icke-verbaliserbart och därmed svårt att synliggöra för omgivningen. För avhandlingen utgick jag från min erfarenhet av att sjunga med barockensemble. Denna erfarenhet speglas genom upplevelsetexter mot fenomenologiska teorier av bland andra Martin Heidegger, Maurice Merleau-Ponty och Julia Kristeva. I det följande presenterar jag närmare tillvägagångssättet, terminologin jag utvecklat samt de resultat jag nått. Jag presenterar även resultaten för de enskilda konserterna, därefter ett bitema i konsertserien samt några observationer om sångarens röstanvändning inom en barockensemble.

\section{Konsert 1: O holder Tag}

I första konserten framförde jag tillsammans med Helsingfors barockorkester Johann Sebastian Bachs (1685-1750) två sekulära bröllopskantater. Min tes var att kantaterna ursprungligen skrevs för kvinnliga sopraner, möjligtvis för Anna Magdalena Bach och Faustina Bordoni. Det finns inga entydiga bevis för tesen men med tanke på stämmornas utformning samt det faktum att bröllopskantaterna inte är kyrklig musik kan man onekligen tänka sig det som en möjlighet. I kantaten Weichet nur, betrübte Schatten (BWV 202) inleder sopranen i en betagande duett med oboen; sättet på vilket dessa stämmor slingrar sig omlott om varandra är till och med sensuellt. När jag sjöng dessa kantater under samma konsert märkte jag att $O$ holder Tag, erwünschte Zeit (BWV 210) var dramatisk och uthållighetskrävande i sångstämman på ett helt annat sätt än Weichet nur. Med tanke på hur de ovan nämnda sångerskorna karaktäriserades av sin samtid tänker jag att Anna Magdalena Bach mycket väl kan ha uruppfört Weichet nur medan Faustina Bordonis röst kunde ha varit den som $O$ holder Tag skrevs för. Den senare innehåller tekniskt svåra fraser med koloratur som sträcker sig ända till trestrukna ciss. Sådana fraser finner man inte i den kyrkliga repertoar Bach skrev för pojksopraner.

\section{Konsert 2: Earthly Angels}

Den andra konserten kom tematiskt sett att bli den centrala i min konsertserie. Även i avhandlingen använder jag notexempel från denna konsert. Repertoaren kom från nunnekloster i norra Italien under 1600-talet, särskilt i Milano och Novara. Det som överraskade mig och kom att påverka mig allra starkast var det uttalat kvinnliga subjektet och den starkt förkroppsligade känslan i repertoaren. Det blev plötsligt uppenbart för mig hur ett kvinnligt subjekt kan framträda och hur jag genom hela mitt instrument kan luta mig emot sångstämman i dessa 1600-talsverk. Samtidigt var jag förundrad över att jag inte framfört eller ens känt till den här repertoaren: varför är den gömd eller till och med bortglömd? Isabella Leonarda (1620-1704), Chiara Margarita Cozzolani (1602- ca. 1677) och Rosa Giacinta Badalla (ca.1660ca. 1710) har visat sig vara utmärkta tonsättare och deras känsla för text, den kvinn- 
liga sopranen och dess koppling till både stråkinstrument och continuostämma är ypperlig.

Under sin storhetstid under 1600-talet var dessa musicerande nunnor välkända i samhället och man kom för att lyssna till dessa jordiska änglars musik från när och fjärran. Nunnorna var avskiljda från sin publik genom en vägg som delade klosterkyrkan i två delar, mellan vilka endast ljudet kunde flöda genom en öppning i väggen högst uppe vid innertaket. Denna vägg mellan chiesa interiore och chiesa esteriore fanns för att nunnorna inte skulle ses sjunga - och därmed öppna munnen - annars skulle de åsamka de manliga åhörarna "syndiga" tankar med denna "sexuella invit". Men om man ser till de möjligheter en dylik vägg skapade för nunnorna så riskerade de inte att få en smutsig kvinnas stämpel, utan istället kunde de förbli subjekt utan manlig närvaro och objektifierande blickar.

Det förkroppsligade uttrycket i början av motetten Volo Jesum av Leonarda är, för denna epok och med tanke på att det är kyrklig musik, ytterst ovanlig. Texten tar tillsammans med frasens uppbyggnad och de extra andningspauserna tag om sångarens hela instrument. Medan ordet "suspiro" sjungs är extra pauser inskrivna. Pauserna kan man förverkliga med hörbara inandningar varpå man kan åstadkomma en särskilt förkroppsligad kvalitet där uttrycket gentemot den centrala manliga gestalten i nunnans liv, Jesus, blir konkret. Jag upplever i dylika passager att hela jag blir indragen i musiken. Den liksom tvingar hela instrumentet med diktion, andning och kroppens tyngd att luta sig mot det musikaliska uttrycket. Det kvinnliga subjektet är alltså särskilt starkt i denna repertoar, allt ifrån sångare och instrumentalister till tonsättarna och de musikaliska ledarna var kvinnliga.

\section{Konsert 3: Vivaldis fickor}

I den tredje konserten framfördes Antonio Vivaldis (1678-1741) oratorium Juditha Triumphans (RV 644) tillsammans med Finländska barockorkestern och Akademiska damkören Lyran. Verket skrevs för flickorna på Ospedale della Pietà i Venedig, där Vivaldi var musiklärare och där det framfördes av en helkvinnlig ensemble. Oratoriet, det enda bevarade av Vivaldi, bygger på en berättelse med en stark kvinna, den bethuliska änkan Judit, som besegrade den assyriska arméns överbefälhavare Holofernes och halshögg honom.

De två saker som var centrala $\mathrm{i}$ konserten var å ena sidan hur vi med kvinnliga röster tolkar ett våldsamt tema och å andra sidan hur tenor- och basstämmorna $\mathrm{i}$ körsatsen bäst förverkligas med en damkör. Körpartiet är skrivet för damkör eftersom alla musikeleverna i La Pietà var kvinnliga och det hade varit otänkbart att ta in män till kören av sedlighetsskäl. I produktionen gjorde vi så att tenorstämman sjöngs av sopraner så att den klingade i sopranhöjd, en oktav ovanför den skrivna tonhöjden. Detta visade sig klinga utmärkt i praktiken. Basstämman sjöngs av andra altarna. Ibland gick stämman ändå för lågt för studentkörens unga altar, så därför arrangerade jag om stämmorna i vissa partier. På så sätt fick även andra altarna sjunga 
på en tonhöjd som kändes bekväm och där deras röst har god hörbarhet. Till min stora glädje kunde jag lägga märke till vilken stärkande inverkan projektet hade på damkörens tilllit till sitt instrument och till det värde det hade redan under barockepoken. Många körsångare uttryckte nämligen sin besvikelse över att det"inte finns repertoar för vår kör inom epoken”, trots att de älskar barock. Under arbetet med musiken kunde jag lägga märka till att körens självförtroende och pondus märkbart växte.

En något olycklig omständighet kring den tredje konserten var problemet med stämningen av två instrument i orkestern. Det ledde till att vi var tvungna att framföra konserten i $415 \mathrm{~Hz}$ istället för $440 \mathrm{~Hz}$ såsom vi hade planerat. Samtliga röster, såväl solister som kör, hade nog klingat bättre i $440 \mathrm{~Hz}$ men tyvärr var detta omöjligt att ordna. Däremot gav det oss en viktig lärdom för framtiden.

\section{Konsert 4: Alcina}

Den fjärde konserten, Georg Friedrich Händels (1685-1759) Alcina (HWV 34), var samtidigt operans finländska uruppförande. Vi framförde operan tillsammans med Vasa stadsorkester under ledning av Aapo Häkkinen. I operan blev det tydligt att en tidig bel canto -teknik redan gjort sitt intåg i London tack vare Händels täta kontakt till Italien och hans användning av italienska sångare. Alcinas roller erbjuder stor vokal briljans med sina många da capo -arior där kunskapen om sopranernas divalater och inbördes rivalitet under Händels tid gav extra inspiration till att göra virtuosa ornament. Att sjunga Händelopera anser jag förutsätter en stadig bel canto -sångteknik men samtidigt en förståelse för stilistiska ideal, det vill säga en förmåga att styra över vibratots användning och smidigt kunna variera mellan tyngd och lätthet i den sjunga frasen. I denna repertoar är inte 1600-talets särskilda sångtekniska finesser längre så tydligt närvarande. Exempelvis trillo med la gorgia -teknik eller särskild rytmisk textbehandling som i italiensk 1600-talsmusik har istället ersatts med särdeles betagande melodier och en tydligare förankring i sångens legatolinje. Alcina sattes upp på festivalen Vasa Baroque och jag upplever genom denna produktion att ledarskapsfrågor återigen kom i fokus. Förutom att jag var solist i rollen som Morgana hade jag även som festivalens konstnärliga ledare huvudansvaret för hela produktionen. Jag märkte att det kräver en alldeles särskild balans mellan dessa två roller men att det ingalunda är en omöjlig kombination. Föreställningen möttes av stor entusiasm och stående ovationer i Vasa stadshus.

\section{Konsert 5: Fest på Tre Kronor! - Hemma ifrämmande land?}

I den femte och sista konserten fokuserade jag på Sveriges drottning Kristina (1626-1689) och de sångerskor hon anlitade. Drottning Kristina var på många sätt en föregångare, särskilt som kvinnlig kulturmecenat. Under hennes tid som Sveriges regent hördes den första professionella kvinnliga sopranen sjunga vid hovet: Anne Chabanceau de la Barre (1628-1688) från Paris. Under Kristinas tid i Rom och ar- 
betet med teatern Tordinona framträdde professionella sångerskor offentligt. Detta skapade stor uppståndelse i staden.

I konserten upplevde jag att utvecklingen från sångsolist till sångerska och konstnärlig ledare lyckats väl: kommunikationen med instrumentalisterna, dansaren och bildkonstnären fungerade på alla sätt mödolöst. Sångens berättelse var drivande och det kändes betydelsefullt att även kunna fläta samman musiken med konstverk som projicerades på videoduk för ett fördjupat uttryck. Även om antalet tonsättare och sångspråk i konserten var stort - detta var för övrigt den enda konserten där svenskspråkig barock hördes - så tycker jag att helheten blev väldigt lyckad.

\section{REFLEKTIONER ÖVER KONSERTERNA}

För mig har konsertserien först och främst varit en fenomenal utvecklingsmöjlighet och mitt mål har hela tiden varit konstnärlig utveckling. För varje konsert har jag gjort något som varit nytt för mig och jag ser att den sångerska, konstnärliga ledare och forskande musiker jag är i dag är tack vare den utveckling som inkluderar både stora framgångar och några smärre missöden jag upplevt med denna konsertserie.

Ett starkt bitema i konsertserien har varit sångarens olika roller i ensemblen. Inom operalitteraturen brukar min rösttyp, alltså en hög lyrisk sopran med anlag för koloratur, förknippas med subrettroller, alltså roller där karaktären är ung, ”den andra" sopranen och ofta ett objekt för den manliga blicken. Rösttypen är alltså inte traditionellt förknippad med styrka, auktoritet eller med en karaktär som driver handlingen framåt som ett starkt subjekt.

Jag har lagt märke till att denna uppfattning om rösttypens generella drag även på ett subtilt plan påverkat konsertseriens bitema. Det förekommer att en soprans klädsel och utseende kommenteras och hon kan uppfattas som avskild från ensemblen, det vill säga så att sopranen sköter enbart sången medan instrumentalisterna - musikerna - sköter om att musiken fungerar. Utgångsläget i bitemat om sångarens olika roller kan alltså betraktas så, att det finns vissa generella föreställningar att bearbeta och komma ifrån. I två av konserterna var jag solist medan jag i de övriga konserterna också hade det konstnärliga ansvaret för repetitionsprocessen. Naturligtvis var det konstnärliga ansvaret mitt för hela konsertserien, men det jag avser är att ingen annan hade blivit utsedd till ledare för dessa konserter.

Under de gångna åren studerade jag även orkesterledning för professor Jorma Panula för att bättre förstå mig på kommunikationen med instrumentalister. Med den erfarenheten samt mina tidigare kyrkomusikstudier arbetade jag fram ett ledarskap som baserar sig på vokalmusikens byggstenar, en noggrant sammansatt ensemble samt ett ömsesidigt förtroende mellan sångare och instrumentalister. Att sångaren samtidigt är den musikaliska ledaren för en grupp instrumentalister och i vissa fall även sångare har sina fördelar då repertoaren består av vokalmusik. Jag 
har i dessa fall färdigställt konsertrepertoaren för de instrumentala verken i repertoaren, ibland efter konsultation med någon av instrumentalisterna. Under repetitionsperioden står jag vänd emot instrumentalisterna så att vi har en visuell kontakt där gester, uttal och frasering kan kommuniceras utan att alltid avbryta musiken. Under repetitionerna knyter vi särskilt noggrant ihop sångarandningen med instrumentalisternas frasering samt textens diktion med exempelvis continuogruppens utformning av arpeggion eller bastonens ansats i början av en fras. Genom textens olika betoningar fogas fraserna samman med baslinjen så att continuogruppen så att säga spelar texten medan jag sjunger den. Detta arbetsskede är särskilt viktigt för sångaren och continuogruppen tillsammans. Då kan vi åstadkomma en gemensam textbehandling som därmed ger utrymme för en tolkning bortom orden. Repetitionsperioden är tillräckligt noggrann för att vi under konserten inte behöver visuell kontakt. Istället kommunicerar vi, liksom jag senare diskuterar kring avhandlingens tema, genom andning och genom att koncentrerat "lyssna in" varandra. Det ger en kammarmusikalisk upplevelse av konserten då vi alla genom detta arbetssätt kan komma till tals.

Peter Spissky diskuterar i sin avhandling huruvida sound eller tillvägagångssätt är det centrala då man framför barockmusik idag. Eftersom det inte finns några exakta angivelser för soundets ideal är det viktigare att bearbeta vad man exempelvis vill åstadkomma med affekter, samt att sångaren är samsjungen med instrumentens klang. Den sångteknik som användes under barocken har jag alltså inte direkt funnit relevant för mitt projekt. Mitt sångtekniska fokus har istället legat på att sångarens tonbildning motsvarar exempelvis violinens eller traversföjtens, inte på att problematisera det faktum att jag är utbildad enligt bel cantons ideal vilket inte var det allmänt vedertagna sångsättet på 1600-talet. Åhöraren idag förväntar sig att sång inom det breda klassisk sångspektret klingar igenkännbart, alltså att en egaliserad röstteknik enligt bel canto -idealet förverkligas. För den sångare som idag sjunger både barock och senare skriven musik blir det då naturligt att använda en bel canto-baserad grundteknik som man sedan enligt den specifika genren kan variera. Ett exempel på det är tonens form ända från dess ansats till vibratots användning och tonens slut. Sammanfattningsvis kan jag för konsertseriens del konstatera att den repertoar dessa kvinnliga sopraner framförde och den musik som nunnorna tonsatte är speciell på många olika vis: den är sångtekniskt krävande med stor tessitura och utmanande koloraturer. Musiken är synnerligen tilldragande i sin innerlighet och affektrikedom.

\section{AvHANDLINGEN: SJUNGA-I-VÄRLDEN- EN FENOMENOLOGISK BETRAKTELSE ÖVER SÅNGARENS INRE ARBETE}

Utgångspunkten för avhandlingen är sångarens inre arbete. Vad gör sångaren utöver det sångtekniska arbetet för att skapa en holistisk, fullödig tolkning av ett musika- 
liskt verk där hela ensemblen är samspelt? Vilka verktyg har sångaren för kommunikationen med såväl instrumentalister som åhörare?

I arbetet med en barockensemble är formatet mindre och kammarmusikaliskt på ett sätt som operasångarens arbete normalt inte är, utöver detta jobbar man ofta utan dirigent. I barockensemblen skapas kommunikation mellan musikerna genom andning, en gemensam stillhet och genom att aktivt"lyssna in" varandra. Även konserterna kan vara i mindre och intimare utrymmen än en operaföreställning. Då jag har studerat sångarens inre arbete är det specifikt denna typ av repetitions- och konsertsituation jag utgått ifrån.

Jag har studerat sångarens inre arbete så att upplevelsetexter speglats mot fenomenologiska teorier. Upplevelsetexterna är observationer jag gjort baserat på upplevelser i typiska situationer med barockensemble: från min egen övningsprocess till arbetet med ensemblen vid repetitionstillfällen och konserter. De fenomenologiska teorier jag använt är av bland andra Martin Heidegger, Maurice Merleau-Ponty, Luce Irigaray och Julia Kristeva, utifrån vilka jag kan beskriva de förspråkliga skeendena som sångarens inre arbete bland annat består av. Jag har även tagit till mig skrifter av framstående musiker såsom Ralf Gothóni och Tom Krause, vilka jag funnit behandlar det inre arbetet med olika ord och definitioner.

De forskningsfrågor jag ställt är:

(1) Vad omfattar sångarens inre arbete?

(2) Hur behandlar sångaren det inre arbetet?

Jag har betraktat det inre arbetet först ur en praktisk synvinkel genom enheten kropp-andning-sinne. Dessa sidor av enheten kan studeras var för sig även om jag ser att enheten ändå inte kan spjälkas upp. Den professionella sångaren behöver i sitt arbete en fungerande enhet kropp-andning-sinne för att kunna förverkliga en djup musikalisk tolkning och en kommunikation med såväl det egna instrumentet som med musiker och åhörare i rummet. I detta skede av den sångliga utvecklingen är tekniken relativt automatiserad så att sångaren förmår behandla tolkningsmässiga och kommunikativa skeenden bakom den. Innan sångaren kommit så långt i sin utveckling kan de olika elementen i enheten kropp-andning-sinne upplevas vara i otakt.

Avhandlingen har strukturerats upp enligt följande: först studeras kroppens roll igenom chora, därefter andning utgående från inspiration och till sist sinne tillsammans med beröring. Andningen är en central del av sångarens tillvaro i musiken och kontakten till instrumentet och de andra i rummet närvarande. Därför väljer jag bort den cartesianska kropp-själ-uppfattningen och introducerar andningen som en koppling mellan kroppen och sinnet.

Kring kropp-andning-sinne finns i sångarens tillvaro sådant som förknippas med en eller flera av sidorna i denna enhet: chora, närvaro, stillhet, flow, expansion, inspiration, beröring, intuition och kommunikation. Enheten spjälks alltså inte upp i 
sina beståndsdelar även om den betraktas från olika synvinklar. Genom den professionella sångarens varande i denna enhet kan tonkroppen tändas. Tonkroppen är inte varje klingande ton, utan den optimala tonen där dessa element i bilden har funnits med i det inre arbetet och förberedelsen.

Utgående från det praktiskt härledda kropp-andning-sinne, skapas det teoretiska sjunga-i-världen. Denna term innefattar följande beståndsdelar:

- chora som utgångspunkt, ur Platons och Kristevas teoretiska referensram

- sångarens varande $i$ och till rummet, enligt Heidegger och Merleau-Ponty

- den klingande tonkroppen, och

- tonkroppens existens $i$ rummet, för alla.

Chora är en term som först användes av Platon som skrev såhär: "Därför måste det som ska ta emot alla sorter i sig vara utanför alla slags former." Kristeva påpekar att chora inte kan ges en uppenbar form. Den definieras för att en meningsgivande process ska kunna ske. I sjunga-i-världen betyder chora ur sångarens synvinkel det som finns innan inspiration och därmed andning sker - innan tonens blivande förankras i kroppen. Där jag med min professionella erfarenhet vet att mening kommer att skapas och därför kan vänta in den.

Merleau-Pontys suis à, alltså till-världen-varo, avser att kroppen tar sig till omgivningen medan Heideggers in-der-Welt-sein, alltså $i$-världen-varo, avser att människan ställer sig $i$ omgivningen och observerar den utgående från sig själv. På detta vis ställer sig även sångaren $i$ rummet. Utgående från denna position tar sig sångaren till sitt instrument, till instrumentalisterna och till åhörarna i rummet. Centrala beståndsdelar för dessa rörelser $i$ och till finns i kropp-andning-sinne och elementen däromkring, bland andra stillhet, beröring och expansion. För dessa rörelser behöver sångaren befinna sig i beredskap, alltså redo att sjunga-i-världen.

Tonkroppen klingar då det inre arbetet i förberedelsen fram till tonens ansats fungerat väl, och därefter finns tonkroppen och därmed sången till för alla $i$ rummet. Den delas av såväl sångare, instrumentalister som åhörare. Denna process, som startar i chora och fulländas i och med tonkroppen, är cyklisk och därmed återkommande till sin natur. Likaså har min behandling av ämnet haft vissa cykliska drag såsom även andningscykeln har.

Sångaren behandlar det inre arbetet på följande sätt:

Genom stillhet inför sången, i chora, kan inspiration väckas. Denna inspiration knyter an till instrumentet genom inandningen och gör sångaren redo för tonen. Sångarens attityd behöver här genomsyras av beredskap inför sången.

Efter en kort stund av stillhet, den förfonatoriska förberedelsen, kan tonkroppen tändas. I denna stilla stund bereds plats för tonen att så att säga anlända uppifrån, denna föreställning har i praktiken visat sig förstärka sångarformanten och sörjer därmed för en god och hörbar klang. Denna stilla stund eller väntan inkluderar 
ett starkt fokus inför den kommande tonkroppen, sångaren är i detta skede mycket koncentrerad.

Den tonkropp som tänds genom tonens ansats beledsagas av en stark enhet kropp-andning-sinne. Sångarens sinnesnärvaro, le sens, i denna enhet skapar liksom en vågrörelse åt den sjungna frasen och hela det musikaliska verket. I den starka närvaron och beröringen kan röstens gräng (alltså Barthes le grain de la voix) skönjas. Denna härrör sig till talet, rösten, rymden där mening skapas. Genom sångarens och instrumentalisternas tolkning skapas då en musikens äkta och berörande mening tillsammans med den gemensamma närvaron i rummet.

Jag avslutar med att citera Giulio Caccinis ord från år 1602 som diskuterar musikens mening och hur sångaren kan skapa den. Här ser jag många paralleller till sjunga-i-världen, alltså varför vi sjunger, vad vi vill uttrycka och hur vi går tillväga:

"Musikens mening är att ge välbehag och att röra själens affekt." 